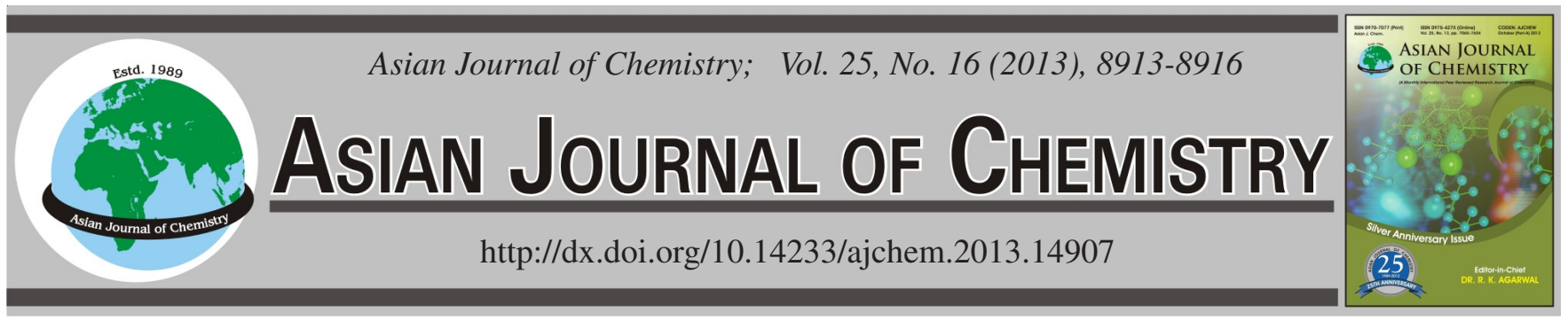

\title{
Spectrophotometric Determination of Citalopram in Pharmaceuticals Using Folin-Ciocalteu Reagent
}

\author{
Asad Raza*and TARiQ MahmoOd Ansari
}

Institute of Chemical Sciences, Bahauddin Zakariya University, Multan 60800, Pakistan

*Corresponding author: Tel: +92 300 9639949; E-mail: asadbzu@yahoo.com

(Received: 4 December 2012;

Accepted: 9 September 2013)

AJC-14079

\begin{abstract}
A simple and selective spectrophotometric method for the determination of citalopram hydrobromide is described. The method is based on the formation of blue coloured chromogen due to reduction of tungstate in Folin-Ciocalteu reagent by citalopram in alkaline medium. The coloured species has an absorption maximum at $730 \mathrm{~nm}$ and the Beer's law obeys over the concentration range of 5-75 $\mu \mathrm{g} \mathrm{mL}$. The limit of detection and quantification value are 3.43 and $11.34 \mu \mathrm{g} \mathrm{mL} \mathrm{m}^{-1}$ respectively. Application of the proposed method to bulk powder and commercial pharmaceutical tablets is also presented. No significant difference was obtained between the results of the proposed method and the official USP method. The procedure described in this paper is simple, rapid and extraction free.
\end{abstract}

Key Words: Citalopram hydrobromide, Folin-Ciocalteu reagent, Spectrophotometry, Pharmaceutical preparations.

\section{INTRODUCTION}

Citalopram, [(RS)-1-[3-(dimethyl amino)propyl]-1-(4fluoro-phenyl)-1,3-dihydroiso benzofuran-5-carbonitrile] (Fig. 1) is a widely used antidepressant. It belongs to the class of selective serotonin reuptake inhibitors (SSRIs) having broad spectrum of therapeutic activity against depressive disorders ${ }^{1}$. It has U.S. food and drug administration (FDA) approval to treat major depression and is prescribed off label for a number of anxiety conditions. Citalopram is approved to treat the symptoms of major depression. Citalopram is frequently used to treat anxiety, panic disorder and body dysmorphic disorder ${ }^{2}$. This drug has been found to greatly reduce the symptoms of diabetic neuropathy ${ }^{3}$ and premature ejaculation ${ }^{4}$. The literature survey show that citalopram hydrobromide is determined by various analytical methods including high performance liquid chromatography ${ }^{5-8}$, micellar electrokinetic chromatographic method $^{9}$, spectrofluorimetric method ${ }^{10}$, LC-MS/MS method $^{11,12}$, fast fourier continuous cyclic voltammetry ${ }^{13}$, capillary electrophoretic method ${ }^{14}$, adsorptive stripping voltametric method $^{15}$, chiral capillary electrophoresis (CE) method ${ }^{16}$, HPTLC $^{17}$ and UV-visible spectrophotometric method ${ }^{18-21}$ in plasma and pharmaceutical dosage forms. In the available literature, the proposed analytical spectrophotometric has not been adopted for the quantities determination of citalopram in pharmaceutical raw and dosage forms.

In the present era our drug market is loaded with fake and substandard drugs. Efforts are therefore made in this work to develop a simple, direct and sensitive analytical method for the determination of citalopram hydrobromide in pharmaceutical formulations. The aim of the present research work is to develop a sensitive and less expensive spectrophotometric method that rely on the use of cheap chemicals and simple techniques but provide accuracy as compared to costly and sophisticated techniques like HPLC.

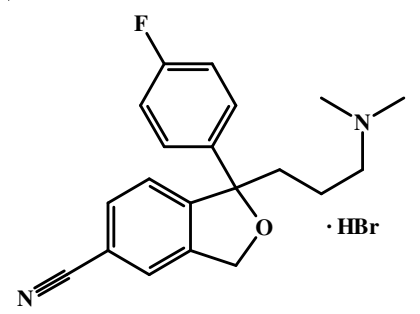

Fig. 1. Chemical structure of citalopram hydrobromide

\section{EXPERIMENTAL}

All absorption spectra were obtained using (U 1100 Hitachi, Japan) spectrophotometer equipped with $1 \mathrm{~cm}$ matched quartz cells.

Chemicals used were of Analytical Grade. Distilled water was used throughout the investigation. Folin-Ciocalteu reagent (Fluka, Germany), sodium hydroxide (Merck, Germany) were of Analytical Reagent Grade and used without further purification. A pure citalopram hydrobromide (pharmaceutical grade) sample was kindly provided by Bio Fine Pharmaceuticals (Pvt.) Ltd. Multan, Pakistan. Three brands 
of tablets, namely, S-pram (BioFine Pharmaceuticals), Cheer (Wilshire Laboratories Lahore, Pakistan) and Cipram (Lundbeck Scientific Karachi, Pakistan) were obtained from commercial sources.

Drug and reagent solutions: A stock solution of citalopram hydrobromide $(1 \mathrm{mg} / \mathrm{mL})$ is prepared by dissolving $100 \mathrm{mg}$ of pure drug in $100 \mathrm{~mL}$ distilled water in a volumetric flask. Working concentrations of citalopram were prepared by dilution of the above stock solution with water. FolinCiocalteu reagent solution $(2 \mathrm{~N})$ is used as such. $\mathrm{NaOH}$ solution $(1 \mathrm{~N}$ ) is prepared by dissolving $4 \mathrm{~g}$ of $\mathrm{NaOH}$ in $100 \mathrm{~mL}$ of distilled water.

Determination of absorption spectra: Citalopram solution equivalent to $10 \mu \mathrm{g} \mathrm{mL}^{-1}$ was mixed with $2 \mathrm{~mL}$ of sodium hydroxide solution and $2 \mathrm{~mL}$ of Folin-Ciocalteu reagent in a $10-\mathrm{mL}$ volumetric flask. After $15 \mathrm{~min}$, the volume was made up to the mark with water and the content was mixed thoroughly. A blank solution was prepared in the same way in the absence of citalopram. This solution was scanned in the range of 400-800 $\mathrm{nm}$ against the reagent blank. Maximum absorption was observed at $730 \mathrm{~nm}$ and was fixed as analytical wavelength.

General analytical procedure: Different aliquots of the working standard of citalopram hydrobromide solution (10 $\mu \mathrm{g} \mathrm{mL} \mathrm{m}^{-1}$ ), ranging from $2-20 \mu \mathrm{g} \mathrm{mL}^{-1}$, were transferred into a series of $10-\mathrm{mL}$ volumetric flasks and the total volume was brought to $10 \mathrm{~mL}$ with water. To each flask, $2 \mathrm{~mL}$ of sodium hydroxide solution and $2 \mathrm{~mL}$ of Folin-Ciocalteu reagent solution were successively added by means of a microburette. The flasks were stoppered, contents were mixed and kept at room temperature for $15 \mathrm{~min}$. The volume was made up to the mark with water and the absorbance of each solution was measured at $730 \mathrm{~nm}$ against a reagent blank.

Assay procedure for tablets: An amount of finely ground tablet powder equivalent to $100 \mathrm{mg}$ of citalopram hydrobromide was accurately weighed into a $100 \mathrm{~mL}$ volumetric flask, the flask was shaken after addition of a $50 \mathrm{~mL}$ of water for about $2.0 \mathrm{~min}$ and finally the volume was made up to the mark with water. The content was kept aside for 5 min and filtered using Whatman No. 42 filter paper. The first 10-mL portion of the filtrate was discarded and a suitable aliquot was used for the assay as described under general analytical procedure.

\section{RESULTS AND DISCUSSION}

The structural features of citalopram allowed the use of Folin-Ciocalteu reagent for its assay. The proposed method is based on the formation of a blue coloured chromogen when citalopram reacted with the Folin-Ciocalteu reagent in the presence of sodium hydroxide. Colour formation may be explained as follows based on the analogy reported by Peterson $^{22}$. Mixed acids in the Folin-Ciocalteu reagent involve the following chemical species:

$$
\begin{gathered}
3 \mathrm{H}_{2} \mathrm{O} \cdot \mathrm{P}_{2} \mathrm{O}_{5} \cdot 13 \mathrm{WO}_{3} \cdot 5 \mathrm{MoO}_{3} \cdot 10 \mathrm{H}_{2} \mathrm{O} \text { and } \\
3 \mathrm{H}_{2} \mathrm{O} \cdot \mathrm{P}_{2} \mathrm{O}_{5} \cdot 14 \mathrm{WO}_{3} \cdot 4 \mathrm{MoO}_{3} \cdot 10 \mathrm{H}_{2} \mathrm{O}
\end{gathered}
$$

Citaloprm probably causes a reduction of molybdate in the Folin-Ciocalteu reagent, thereby producing one or more reduced species that have a characteristic intense blue colour. Fig. 2 shows the absorption spectrum of the reaction product.

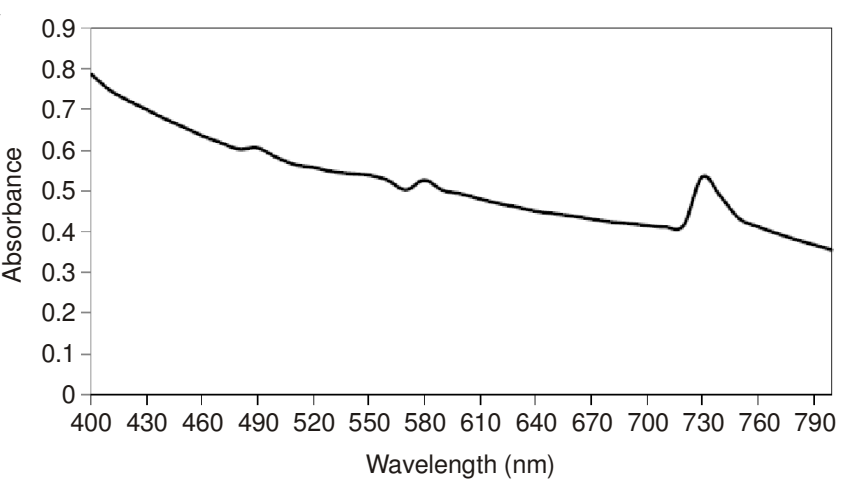

Fig. 2. Absorption spectrum of citalopram and Folin-Ciocalteu complex

Optimization of the reaction conditions: Optimum conditions were fixed by varying one parameter at a time while keeping other parameters constant and observing their effect on the absorbance at $730 \mathrm{~nm}$.

Effect of colour producing regent on the formation of colour complex was studied. Different volume of $2 \mathrm{~N}$ FolinCiocalteu reagent was used without further dilution. It was observed that $2 \mathrm{~mL}$ volume of Folin-Ciocalteu reagent is sufficient for the maximum colour development as shown in Fig. 3. To find a suitable medium for the reaction different aqueous bases were investigated. Best results were obtained with $1 \mathrm{~N}$ sodium hydroxide. It was found that maximum and constant absorbance was obtained in the concentration range of 0.5 to $5 \mathrm{~mL}$ of $1 \mathrm{~N}$ sodium hydroxide thus $2 \mathrm{~mL}$ of $1 \mathrm{~N}$ sodium hydroxide was fixed as optimal as shown in Fig. 4.

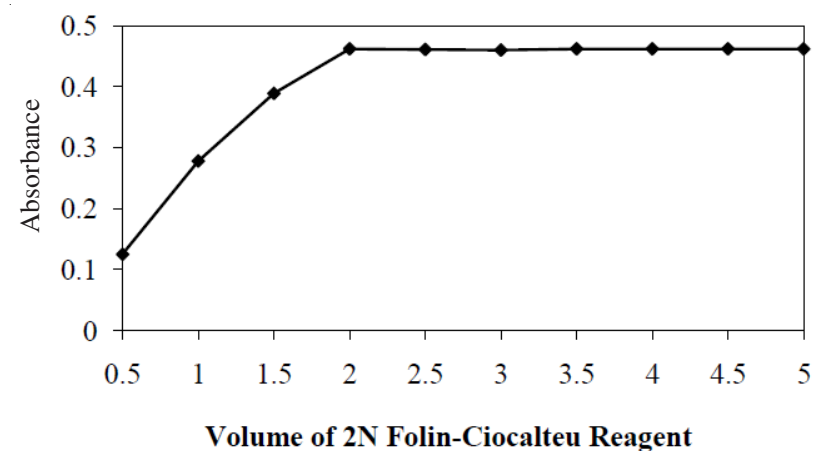

Fig. 3. Effect of volume of reagent on color development

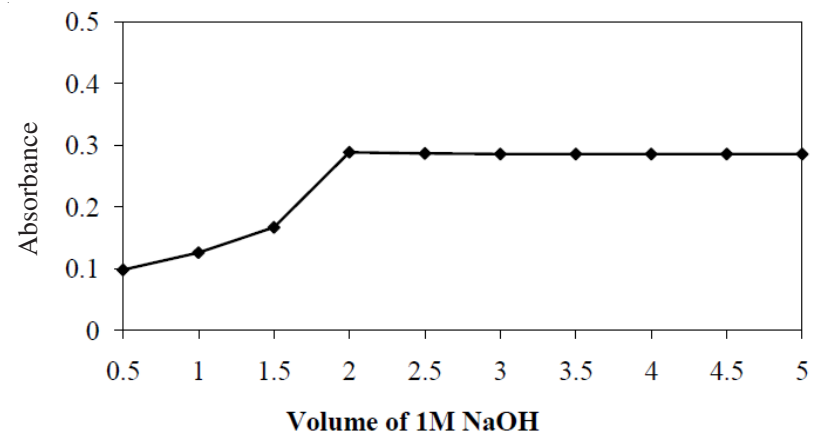

Fig. 4. Effect of volume of base on color development

The reaction time was studied by measuring the absorbance of the blue chromogen after mixing the reactants over a period from 1 to $30 \mathrm{~min}$. Maximum colour developed in 15 min and was stable for at least $90 \mathrm{~min}$ as shown in Fig. 5. 
Measurements were therefore made only after 15 min throughout the investigation.

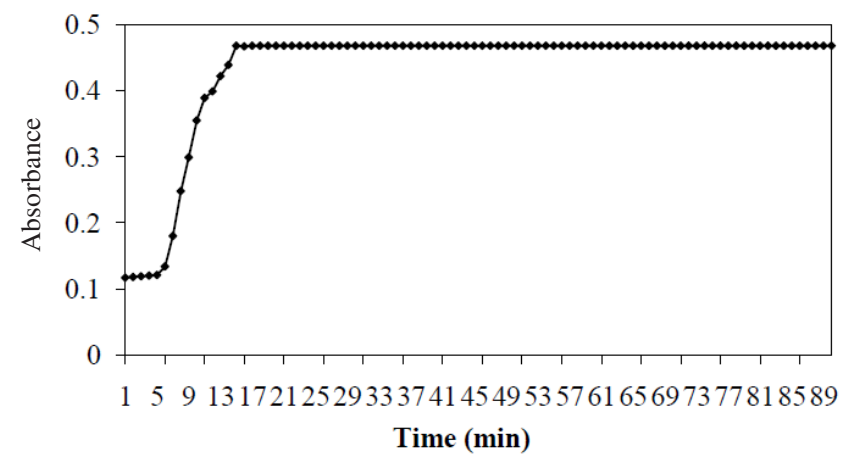

Fig. 5. Effect of time on color development and stability of color

Highest sensitivity was obtained when the order of reactants addition was maintained as described in the general analytical procedure and the same was followed throughout the investigation.

Interference effect: More than $99.90 \%$ recovery of citalopram hydrobromide was obtained in the presence of various excipients and additives used in tablet formulations such as microcrystalline cellulose, lactose monohydrous, povidone, magnesium stearate, starch and primojel. Under the experimental conditions applied, to a known amount $(10 \mu \mathrm{g} / \mathrm{mL})$ of drug excipients in different concentrations were added and analyzed. Results of the recovery analysis are presented in Table-1. Excipients up to the concentrations shown in the Table- 2 have no interference with the assay. In addition recoveries in most cases were $100 \%$ and the lower values of the RSD indicate the good precision of the proposed method.

Analytical Applications: Pharmaceutical formulations (Cheer, S-pram and cipram tablets) containing citalopram hydrobromide $20 \mathrm{mg} / \mathrm{tab}$ were analyzed by the proposed

TABLE-1

STATISTICAL ANALYSIS OF CALIBRATION GRAPH AND ANALYTICAL DATA FOR THE COMPLEX OF CITALOPRAM WITH FOLIN-CIOCALTEU REAGENT

\begin{tabular}{lc}
\hline Parameter & Value \\
\hline$\lambda_{\max }(\mathrm{nm})$ & 730 \\
Beer's law limits $(\mu \mathrm{g} / \mathrm{mL})$ & $5-75$ \\
Molar absorptivity $\left(\mathrm{L} \mathrm{mol}^{-1} \mathrm{~cm}^{-1}\right)$ & $1.40 \times 10^{4}$ \\
Sandell's sensitivity & $2.22 \times 10^{-2}$ \\
Limit of Detection $(\mu \mathrm{g} / \mathrm{mL})$ & 3.43 \\
Limit of Quantification $(\mu \mathrm{g} / \mathrm{mL})$ & 11.34 \\
Slope & 0.11 \\
Intercept & -0.11 \\
Correlation coefficient & 0.999 \\
\hline$(\mathrm{n}=5)$ &
\end{tabular}

TABLE-2

PERCENT RECOVERY OF CITALOPRAM HYDROBROMIDE IN THE PRESENCE OF EXCIPIENTS/ADDITIVES

\begin{tabular}{lcc}
\hline $\begin{array}{l}\text { Excipients/ } \\
\text { additives }\end{array}$ & $\begin{array}{c}\text { Amount taken } \\
(\mu \mathrm{g} / \mathrm{mL})\end{array}$ & $\begin{array}{c}\text { Recovery } \\
(\% \pm \text { S.D. })\end{array}$ \\
\hline Microcrystalline cellulose & 460 & $101.67 \pm 0.46$ \\
Lactose monohydrous & 500 & $100.71 \pm 0.43$ \\
Povidone, & 300 & $99.87 \pm 0.35$ \\
Magnesium stearate & 500 & $100.75 \pm 0.64$ \\
Starch & 500 & $100.89 \pm 0.60$ \\
Primojel & 200 & $100.24 \pm 0.48$ \\
Titanium dioxide & 100 & $100.04 \pm 0.76$ \\
\hline
\end{tabular}

method and the accuracy was tested by the standard additions method in which variable amounts of pure drug were added to the previously analyzed portion of pharmaceutical formulations. The results shown in Table- 3 confirm that the excipients and additives used in tablet formulations do not interfere with the assay of citalopram by the proposed method. The proposed method is highly sensitive; therefore it may be easily used for the routine analysis of citalopram hydrobromide in pure form and in its pharmaceutical preparations. The proposed method was applied to determine citalopram hydrobromide in pharmaceutical preparations, the official U.S.P. ${ }^{23}$ method being used for comparative assay. The results are presented in Table-4. The performance of the method was estimated by student-t values and F-ratio tests. At a $95 \%$ confidence level, the calculated $t$ - and F-values did not exceed the theoretical values, indicating that the proposed and the official methods are equally accurate. The proposed method is favourably compared with other existing spectrophotometric methods as shown in Table-5.

Validation of the proposed method: The proposed Spectrophotometric method was validated with respect to linearity range, accuracy, precision, limit of detection (LOD) and limit of quantitation (LOQ).

TABLE-4

ALAYSIS OF COMMERCIAL DOSAGE FORMS BY PROPOSED METHOD AND OFFICIAL METHOD ${ }^{22}$

\begin{tabular}{lcc}
\hline \multirow{2}{*}{ Sample } & \multicolumn{2}{c}{ Recovery $^{\mathrm{a}} \pm$ S.D. \% } \\
\cline { 2 - 3 } & Official method (USP 2009) $^{\text {Proposed method }}$ \\
\hline Cheer tablets $^{\mathrm{b}}$ & $100.32 \pm 0.47$ & $100.24 \pm 0.38$ \\
$\mathrm{~T}$ & & 0.45 \\
$\mathrm{~F}$ & & 1.98 \\
$\mathrm{~S}-$ Pram tablets & $\mathrm{b}$ & $99.28 \pm 0.47$ \\
$\mathrm{~T}$ & & 0.26 \\
$\mathrm{~F}$ & & 1.33 \\
Cipram tablets & \\
$\mathrm{t}$ & $100.78 \pm 0.23$ & $99.87 \pm 0.26$ \\
$\mathrm{~F}$ & & 0.75 \\
\hline
\end{tabular}

${ }^{\mathrm{a}}$ Mean \pm standard deviation of five determinations; ${ }^{\mathrm{b}}$ All tablets contain citalopram hydrobromide equivalent to $20 \mathrm{mg}$ citalopram base

The student t-test and F-test were calculated using MS Ecxel 2007.

\begin{tabular}{|c|c|c|c|c|c|c|}
\hline \multicolumn{7}{|c|}{$\begin{array}{c}\text { TABLE-3 } \\
\text { RESULTS OF RECOVERY AND PRECISION }\end{array}$} \\
\hline Ingredients & $\begin{array}{l}\text { Amount of drug }(\mathrm{mg}) \\
\text { in formulation }\end{array}$ & $\begin{array}{l}\text { Amount added } \\
(\mathrm{mg})\end{array}$ & $\begin{array}{c}\text { Amount } \\
\text { recovered }(\mathrm{mg})\end{array}$ & Recovery (\%) & $\begin{array}{l}\text { Precision (intra } \\
\text { Day)* }\end{array}$ & $\begin{array}{l}\text { Precision (inter } \\
\text { Day)* }\end{array}$ \\
\hline \multirow{3}{*}{ Citalopram } & 20 & 5 & 25.05 & 100.2 & 1.06 & 0.97 \\
\hline & 20 & 10 & 29.76 & 99.20 & 0.98 & 1.12 \\
\hline & 20 & 15 & 34.82 & 99.48 & 0.75 & 0.78 \\
\hline
\end{tabular}


TABLE-5

COMPARISON OF SPECTROPHOTOMETRIC METHODS WITH NEWLY PROPOSED METHOD

\begin{tabular}{lcclll}
\hline$\lambda_{\text {max }}(\mathrm{nm})$ & $\begin{array}{c}\text { Beer's law } \\
\text { limit }(\mu \mathrm{g} / \mathrm{mL})\end{array}$ & $\begin{array}{c}\text { Molar absorptivity } \\
\left(\mathrm{L} \mathrm{mol}^{-1} \mathrm{sm}^{-1}\right)\end{array}$ & Color producing Reagent & Remarks & Reference \\
\hline 240 & $4-40$ & $1.04 \times 10^{2}$ & UV method & Excipients may interfere & 19 \\
590 & $10-250$ & $3.3 \times 10^{3}$ & DDQ & Less sensitive & 20 \\
570 & $8-240$ & $4.2 \times 10^{3}$ & TCNQ & Less sensitive & 21 \\
480 & $1.0-7.0$ & $2.10 \times 10^{4}$ & Bromate-bromide mixture & Mixture of reagent use and involve multi steps & 22 \\
510 & $0.6-6.2$ & $7.30 \times 10^{4}$ & 1,10 -phenanthroline & Involve three reagents and require 20 min. & 22 \\
730 & $5-75$ & $1.40 \times 10^{4}$ & Folin-Ciocalteu reagent & $\begin{array}{l}\text { Highly sensitive single step reaction and } \\
\text { require only 15 min to develop color. }\end{array}$ & $\begin{array}{c}\text { Current } \\
\text { work }\end{array}$ \\
\hline
\end{tabular}

Linearity and range: The prepared aliquots of drug solution $\left(5-75 \mu \mathrm{g} \mathrm{mL}^{-1}\right)$ were scanned for absorbance maximum value at $730 \mathrm{~nm}$. The absorbance range was found to be $0.116-$ 2.21. These solutions obeyed Beer-Lambert's law in above concentration range with regression of 0.9999 .

Accuracy and precision: Accuracy and precision were investigated by analyzing citalopram tablets (i.e. $20 \mathrm{mg}$ tablet) in three independent replicates on the same day (intraday accuracy and precision) and on three consecutive days (Inter-day accuracy and precision). The data evaluated were summarized in Table-3.

Intra-day and inter-day relative standard deviation (RSD) values and also the low RSD values obtained from the analysis of the pharmaceutical formulations (Table-4) indicated good intermediate precision of method.

To validate prediction ability of suggested method, different concentrations of citalopram samples were prepared and analyzed. The results were satisfactory. Using standard addition technique, the method was further validated. The standard addition technique was carried out by adding excipients with the addition of citalopram at $25 \%$ (5 mg), $50 \%$ $(10 \mathrm{mg})$ and $75 \%(15 \mathrm{mg})$, respectively in sample solution. The percent recoveries of the three concentrations were found to be close to $100 \%$, indicative of high accuracy.

Limit of detection and limit of quantification: LOD (k $=3.3)$ and LOQ $(\mathrm{k}=10)$ of the method were established according to ICH definitions. LOD and LOQ of method are reported in Table-2. In this study, LOD and LOQ were based on the standard deviation of the response and the slope of the corresponding curve using the following equations.

$$
\mathrm{LOD}=3.3 \mathrm{~S} / \mathrm{M} ; \mathrm{LOQ}=10 \mathrm{~S} / \mathrm{M}
$$

where $\mathrm{S}$ is the standard deviation of the absorbance of the sample and $\mathrm{M}$ is the slope of the calibrations curve.

\section{Conclusion}

Based on the experimental results, it can be concluded that the newly proposed spectrophotometric method for the determination of citalopram hydrobromide is rapid, accurate, extraction free and economical. The simplicity, sensitivity and selectivity make the method a suitable alternative to the HPLC methods. Other characteristics such as short performance time, ease of handling and non-usage of organic solvents, also suggest this procedure as a routine laboratory method. Therefore, the proposed method can be adopted for the assay of citalopram hydrobromide in quality control laboratories where modern instruments are not available.

\section{ACKNOWLEDGEMENTS}

The work reported in this paper is a part of Ph.D. Thesis of Mr. Asad Raza. Thanks are due to BioFine Pharmaceuticals Ltd, Multan for providing instrumental facilities to carry out this work. The authors are also grateful to the Institute of Chemical Sciences, Bahauddin Zakariya University, Multan, Pakistan for providing support and laboratory facilities.

\section{REFERENCES}

1. L.L. Brunton, K.L. Parker, D.K. Blumenthal and I. Buxton, Goodman \& Gilman's, The Pharmacological Basis of Therapeutics, McGraw-Hill, New York (2008).

2. http://www.rxlist.com/celexa-drug.htm

3. S.H. Sindrup, U. Bjerre, A. Dejgaard, K. Brosen, T. Aaes-Jorgensen and L.F. Gram, Clin. Pharmacol. Ther, 52, 547 (1992).

4. M. Atmaca, M. Kuloglu, E. Tezcan and A. Semercioz, Int. J. Impot. Res., 14, 502 (2002).

5. J. Menegola, M. Steppe and E.E. Schapoval, J. AOAC, 91, 52 ( 2008).

6. S.V. Gandhi, N.D. Dhavale, V.Y. Jadhav and S.S. Sabnis, J. AOAC, 91, 33 (2008).

7. R. Nageswara Rao and A.N. Raju, J. Sep. Sci., 29, 2733 (2006).

8. R.S. Das, Y.K. Agrawal and P. Prajapati, Int. J. Pharm. Sci. Res., 3, 177 (2012).

9. J.R. Flores, A.M.C. Salcedo, M.J.V. Llerena and L.M. Fernández, J. Chromatogr. A, 1185, 281 (2008).

10. S.G. Vasantharaju, S.L. Prabu and A. Jacob, Indian J. Pharm. Sci., 70, 647 (2008)

11. G. Frison, D. Favretto, S. Vogliardi, C. Terranova and S.D. Ferrara, Ther. Drug Monit., 30, 467 (2008).

12. X.Q. Cao, X.Y. Chen, Y.F. Zhang and D.F. Zhong, Yao Xue Xue Bao., 42, 450 (2007).

13. P. Norouzi, P. Daneshgar, M.R. Ganjali and A. Moosavi-Movahedi, J. Braz. Chem. Soc., 18, 231 (2007).

14. E. Satana, U.D. Uysal, N. Goger and M. Tuncel, Chromatographia, 64, 317 (2006).

15. H.P.A. Nouws, C.D. Matos and A.A. Barros, Anal. Lett., 39, 1907 (2006).

16. S. Andersen, T.G. Halvorsen, S.P. Bjergaard, K.E. Rasmussen, L. Tanum and H. Refsum, J. Pharm. Biomed. Anal., 33, 263 (2003).

17. C. Saravanan, M. Thamizhmozhi, C.A.S. Kumar, C. Sudhakar, B. Rajesh and G.S. Kumar, J. Adv. Scient. Res., 3, 62 (2012).

18. G.V. Sagar, Asian J. Chem., 16, 1928 (2004).

19. A. Raza, Chem. Pharm. Bull., 54, 432 (2006).

20. A. Raza, T.M. Ansari and S.B. Niazi, J. Chem. Soc. Pak., 30, 241 (2008).

21. B. Narayana and K. Veena, J. Mex. Chem. Soc., 54, 98 (2010).

22. G.L. Peterson, Anal. Biochem., 100, 201 (1979).

23. United States Pharmacopeia USP 32, NF 27, p. 1948 (2009) 